Orbis Tertius

ISSN: 1851-7811

publicaciones@fahce.unlp.edu.ar

Universidad Nacional de La Plata

Argentina

\title{
Gombrowicz y los clásicos
}

Fernández, Tomás

Gombrowicz y los clásicos

Orbis Tertius, vol. 25, núm. 31, 2020

Universidad Nacional de La Plata, Argentina

DOI: https://doi.org/10.24215/18517811e148

Atribución no comercial compartir igual (CC BY-NC-SA) 4.0 
Artículos

\section{Gombrowicz y los clásicos}

Gombrowicz and the Classics

Tomás Fernández

DOI: https://doi.org/10.24215/18517811e148

Universidad de Buenos Aires - CONICET, Argentina

tomas.fernandez@conicet.gov.ar

Recepción: 30 Julio 2019

Aprobación: 30 Marzo 2020

Recepción: 30 Julio 2019

Aprobación: 30 Marzo 2020

\section{Resumen:}

Este artículo se propone abordar la complicada relación de Witold Gombrowicz con la tradición. A tal fin, subrayo el modo en que le resulta funcional subvertir la perspectiva convencional sobre la 'vulgaridad' y las clases populares, comparándolo con un autor que, aparentemente, se halla en sus antípodas: Marcel Proust. Si bien las referencias a autores latinoamericanos son limitadas, este artículo pretende iluminar el rol de la tradición en culturas marginales como la argentina y, subsidiariamente ${ }^{1}$, poner de manifiesto el problema de la relación entre el autor 'inmaduro' argentino y la tradición.

Palabras ClaVE: Gombrowicz, Tradición, Spivak, Inmadurez, Clásicos.

\section{Abstract:}

This article aims to tackle Witold Gombrowicz's complex relation with tradition. To this end, it shows how Gombrowicz finds it useful to subvert the conventional viewpoint on 'vulgarity' and the popular classes, in comparison with an author who appears to be a complete opposite: Marcel Proust. Although references to Latin American authors are few, this article purports to highlight the role of tradition in marginal cultures, such as the Argentine; and, as a result ${ }^{2}$, to shed light on the relation between the Argentine 'immature' author and tradition.

KEYworDs: Gombrowicz, Tradition, Spivak, Immaturity, Classics.

¿O por fin, la mercenaria sirvienta, ser carente de voz?

(Gombrowicz, 2014, p. 145) ${ }^{3}$

\section{LO BAJO, LO VULGAR Y EL BUEN GUSTO}

Gombrowicz tiene conciencia de que -lejos de ser objetiva y permanente- la hermosura, como la verdad, se construye en un proceso social en el que interviene la tradición literaria, la clase, la historia. Una hermosura radiante al modo de un renacentista no le parecería productiva. Tampoco la hermosura sublime de la maldad, muy explotada en el siglo XIX. La hermosura de la vulgaridad y lo feo, en cambio, que es ella misma ruin y baja, lo obsesiona.

Esta predilección no es ciertamente exclusiva de Gombrowicz. ${ }^{4}$ Para resaltar su especificidad, puede comparárselo con un autor entre varios posibles (Musil y Céline, por ejemplo): en este caso, Marcel Proust.

La perspectiva sobre lo bajo, pese a ser peculiar y sesgada en los dos, se manifiesta en ellos de modo muy diverso. Los personajes de Proust aman a las criadas como grandes señores, ocultándoles su gran situación social (Charles Swann, el Señor de Charlus) y escamoteando frente a sus “iguales", la gente de monde (como Proust consideraba a su público) los rasgos auténticamente vulgares de su personalidad. Son personajes que se ponen y se sacan una máscara según el ambiente en que se muevan, adaptándose a las diferentes esferas. 
Charlus no ignora que, en última instancia, ningún noble realmente grande puede ser previsible, confiable y distinguido todo el tiempo. Su identidad es oscilante y no está dada a priori. Proust integra la vulgaridad y la perversión al conjunto, volviéndola parte orgánica de una unidad mayor; podemos pensar en sus reflexiones sobre el sadismo y el melodrama, que se aplican mutatis mutandis a su propio arte narrativo. ${ }^{5}$ No solo eso: sus personajes buscan distinguirse de los snobs por otros medios; en parte, actúan la vulgaridad por afán de distinción, lo que no significa, ciertamente, que desconozcan la tradicional antítesis "vulgaridad - distinción", mencionada explícitamente en varios pasajes. ${ }^{6}$

En cambio, los personajes de Gombrowicz, incluyendo el principal, Gombrowicz mismo, se mimetizan o fingen mimetizarse de modo total con las criadas, los marineros, etc. Incluso al escribir los evoca con un estilo que es bajo, pero no al modo del estilo "bajo" en la teoría clásica de los tres estilos, sino rastrero y vil. La mimetización, sin embargo, no es total. En Gombrowicz, más que integración al modo proustiano hay yuxtaposición y collage. En el cuento "En la escalera de servicio" (Gombrowicz, 2015), el protagonista Filip se comporta, cuando está con las criadas, como el gran señor que en algún punto sigue siendo. Por eso las criadas lo atacan. No lo respetan ni como señor ni como criado. Personajes como Filip no guardan las formas y son vulgares incluso para el canon de los personajes vulgares.

Los personajes de Proust, con altibajos, se adaptan con gracia y talento a los distintos ambientes; nunca son falsos, ni siquiera cuando actúan. Los de Gombrowicz, en cambio, están fuera de lugar en cualquiera de ellos; siempre son falsos, en particular cuando son espontáneos. Si el narrador de En busca del tiempo perdido oculta sus tendencias vulgares -o, en su caso, las elevadas- por conciencia de un todo mayor, que aprecia y desprecia en una perspectiva justa, en Gombrowicz solo el buen gusto es motivo de vergüenza.

Conviene advertir, aunque sea evidente, que la fascinación por el "pueblo llano" de Proust y Gombrowicz tiene muy poco en común con la literatura naturalista, obrerista y comprometida de un Zola, un Gorki o un Andreiev, ${ }^{7}$ quienes resaltan la hermosura interna, etc. Proust y Gombrowicz, en cambio, toman a las costureras, choferes de ómnibus, lacayos y ascensoristas como otros tantos objets trouvés, en sentido surrealista, y no, si se permite el juego de palabras, como sujets trouvés; cuando Proust o Gombrowicz los citan, los dotan de un aura nueva. Solo así les dan voz, al crearles un público (y ser ellos mismos sus primeros oyentes).

Para retomar las categorías de William Miller en su Anatomía del asco, autores como Zola minimizan el hedor que los obreros urbanos adquieren después de la Revolución industrial y el advenimiento de la democracia:

The advance of civility and refined taste [...] did help somewhat to transform the coarse but bearable odor of the peasant into the more dangerous odor of the urban worker who bore more than his share of the stench of crowded urban spaces. But it was the advent of democratic principles that finally made ill manners and vulgarity not just a source of comedy but of terror and threat to those above. And that's when the working class began to reek seriously, either of filth or of cologne (Miller, 1997, p. 253-254).

En opinión de Miller, la democracia es determinante en el cambio: "democracy not only worked to ensure the equitable distribution of contempt across class boundaries but also produced the conditions that transformed the once benign complacent contempt or indifference of the upper classes into a more malign and deeply visceral disgust" (Miller, 1997, p. 252). Por el contrario, podría argumentarse que la concentración de trabajadores urbanos y el aumento de su participación en la producción son anteriores -en tiempo y relevancia- al "advenimiento de principios democráticos" dentro de la evolución del sentimiento de asco.

Cito largamente a Miller para anticipar una línea que retomaré sobre el final: la de que gran parte del naturalismo, al contrario de lo que Auerbach piensa, no le da voz a ningún sujeto popular verosímil o real, sino que provee de un producto para una serie de clientes (una clase lectora bien determinada, como señala Benjamin al ocuparse de los Travailleurs de la mer). ${ }^{8}$ Dicen lo que otros quieren oír, lo que les aterra oír pero consideran cierto. Gombrowicz pone en duda esta cualidad de narrar lo vulgar. No escribe lo que el lector 
quiere leer, aunque lo tema; su perspectiva nunca es complaciente y su representación de lo bajo no toma puntos de vista prestados, que en definitiva se corresponden con otros sujetos (que lo reifican).

Ni Gombrowicz ni Proust idealizan al modo de Zola. Su clase baja huele y es plenamente sexuada. Así, ya en un primer nivel, se desmarcan mediante una perspectiva peculiar sobre la vulgaridad y las clases populares.

En este contexto, integran a los marineros, obreros y sirvientas en la trama sentimental y sexual de sus personajes. No es casual, en este punto, que los varones mismos (objeto de temor sexual, por ejemplo, en Dickens), ${ }^{9}$ sin importar su clase de pertenencia, no sean percibidos como amenazantes, a pesar de su sexualidad activa y en algunos casos voraz. Es cierto que los encuentros relativamente fugaces y clandestinos no desembocan en uniones durables, que afecten la estructura de distribución del capital y alteren la reproducción social, ${ }^{10}$ algo que, por lo demás, no preocupa excesivamente a los narradores. También el homoerotismo juega aquí un papel importante.

\section{EL CENTRO Y LA PERIFERIA}

El narrador de En busca del tiempo perdido declara sin ningún rodeo su predilección por las clases populares, subrayando al pasar el desprejuicio aristocrático frente a los subalternos, que lo diferencia del bourgeois atemorizado:

Yo nunca había hecho diferencia entre los obreros, los burgueses y los grandes señores, y habría tomado indiferentemente a unos y otros por amigos, con una cierta preferencia por los obreros y después de ellos por los grandes señores, no por gusto, sino sabiendo que se puede exigir de ellos más amabilidad frente a los obreros de la que obtiene de los burgueses. ${ }^{11}$

El extraordinario Señor de Charlus, por su parte, llega mucho más lejos. Para empezar, desaira a la princesa de Guermantes al no acudir a sus citas, con el único fin de ir a la caza de controladores de autobús o porteros de edificios. En una ocasión, el narrador intenta consolar a la princesa enamorada. Para "ahorrarle las decepciones que en mi opinión le esperaban", asegura el narrador, "le dije que ciertos hombres, y frecuentemente los más notables por la inteligencia y los más delicados de sensibilidad, no podían solicitar la satisfacción de sus deseos más que a mujeres extremadamente vulgares, a jovencitas, a criadas, en ocasiones a jovencitas de las calle" ${ }^{12}$ Agrega que Charlus puede ser uno de esos hombres. De modo típico, el tono de la narración permanece elevado y en equilibrio. Los desórdenes, que son muy reales, se mantienen bajo una superficie en apariencia apolínea. La desproporción entre tono y trama es perfecta, y espeja la discontinuidad que existe desde un punto de vista sintáctico entre distintas secciones de la obra (por ejemplo, entre "Combray" y "Un amor de Swann"). En esto radica una de sus grandes peculiaridades. Proust elabora una verdad temblorosa y susurrante, engañosa, que depende tanto del recuerdo lateral como del chisme o de la maledicencia, capaz de disimular agitaciones que un autor realista típico habría narrado de manera tumultuosa. En esto, sin embargo, se encuentra en las antípodas del maestro del understatement en lengua inglesa, Henry James; mientras este recomendaba "dramatizar más”, Proust practica el "dramatizar menos", y presenta lo dramático a través de diversos matices, dándolo por supuesto y tornándolo inaccesible al conocimiento (salvo, de nuevo, a través del chisme, el recuerdo lateral, etc.).

El gusto de Gombrowicz por lo bajo es muy distinto. Las citas que siguen pertenecen a un cuento recién mencionado, "En la escalera de servicio", de 1929 (Gombrowicz, 2015), que se inicia con referencias a París y a un cargo del narrador y protagonista, Filip, en el Ministerio de Relaciones Exteriores (2015, p. 113). En este y otros puntos, Filip se asemeja a otro héroe de Proust, a saber, Swann, que se codea con cocottes de la peor calaña, que lo consideran un Don Nadie, y a continuación visita a duquesas y princesas que no solo lo veneran, también están enamoradas de él; el mismo desprecio, debido a la ignorancia de su situación social, le testimonian los Verdurin al Señor de Charlus en Sodoma y Gomorra.

A diferencia de los héroes proustianos, Filip no se conforma con París. "Y era precisamente ese ritmo [el de París] el que me hacía sufrir, porque yo buscaba otro ritmo, otra melodía...” (2015, p. 114). La vulgaridad 
de París, suficiente para un Charlus, a él no le basta; para un polaco, sugiere el texto, no se trata de una ciudad lo suficientemente común. Vuelve a Polonia y acosa sin cesar a todo tipo de empleadas domésticas: "en los últimos años debo de haber abordado por lo menos a mil quinientas criadas" (2015, p. 114). (La reciente publicación de Kronos documenta que Gombrowicz mismo se relacionó en Polonia con numerosas sirvientas).

La atracción que lo bajo ejerce en alguien de posición social elevada le parece en extremo natural: "Y no era a pesar de, sino más bien precisamente por pertenecer al grupo de funcionarios más distinguidos del Ministerio de Asuntos Exteriores por lo que amaba a las criadas con la faja mal puesta" (2015, p. 116, mis itálicas), "los monstruos de la escalera de servicio que pululaban en torno a los mercados" (2015, p. 116). La paradoja de amar a las "criadas con la faja mal puesta" no a pesar de, sino por pertenecer a la cima de la jerarquía, sigue un patrón repetido. El proceso de civilización, que extendió modales en un principio privativos de una clase aristocrática dirigente, devaluó esos mismos modales en un principio distintivos. Como contraste, y especialmente a partir del s. XIX, las mismas clases que antes se diferenciaban por sus "buenos" modales, empezaron a diferenciarse por "malos" modales, que ofrecían un contraste con su situación objetiva de clase. Por ese motivo, un aristócrata puede (y en cierto sentido, debe) escribir de modo vulgar, mientras que alguien con un capital cultural menos afirmado solo puede permitirse formas admitidamente cultas. Así el aristócrata supera con elegancia el riesgo del esnobismo, practicando un esnobismo de otro orden: el de comportarse como las clases populares por afán de distinción y, en particular, de distinguirse de los burgueses y de los snobs que los desprecian. En cierto sentido, es un snob al cuadrado.

Finalmente, y para guardar las apariencias, Filip se casa. Con su nueva mujer, "todo tenía nombres extranjeros, desde la manicure hasta la permanente, pasando por el savoir-vivre y el bon ton. También yo me había vuelto europeo, todo lavado y reluciente" (2015, p. 119). Lo francés (y europeo por antonomasia), que él había expulsado por la puerta al abandonar París, vuelve a entrar por la ventana apenas se casa.

\section{LA CIVILIZACIÓN}

La mención del francés no es casual. Para su importancia en la "civilización”, especialmente la alemana, cf. Elias (2012). En Argentina puede recordarse el celebérrimo "On ne tue point les idées" de Sarmiento, que sigue estudiándose en las escuelas, o el primer libro de Victoria Ocampo, ya en la década de 1920, De Francesca a Beatrice (escrito en francés, pero publicado en castellano en 1924). Contra la primera cita se alza Piglia. Contra la segunda, Raúl González Tunón: "Estamos en condiciones de asegurar que antes de la aparición del libro De Francesca a Beatrice, el Dante ya era conocido y comentado en el mundo" (1933). Las connotaciones patricias y antipopulares del francés estaban a flor de piel. Otro dato curioso: la primera amistad intelectual de relieve de Victoria Ocampo, y autor del epílogo que facilitó la circulación de su primer libro, es nada menos que Ortega y Gasset, el anti-Gombrowicz de quien también se burla a cada oportunidad Piglia en Respiración artificial. Las series se extienden en el tiempo. Proust, por muchas semejanzas externas que tuviera con Ocampo, habría tomado el partido popular (como Borges que, según una entrevista, quería afiliarse al grupo de Boedo y no al de Florida).

Filip "evoluciona”. Empieza a apreciar la pulcritud y odiar la suciedad. En un momento llega a pedirle a su mujer que desprecie la suciedad. La respuesta de ella no se hace esperar: "-Me asombra que tomes tan a pecho esas cosas - me respondió gélidamente-, yo no desprecio eso, sencillamente lo ignoro” (Gombrowicz, 2015, p. 125).

La ignorancia pura y simple de la mujer de Filip permite clasificarla, según la tipología que reinterpreta Slavoj Žižek en las páginas iniciales de Less than Nothing, como idiota: quien se halla "simply alone, outside the big Other” (Žižek, 2012, p. 2). ${ }^{13}$ Gombrowicz mismo pretendería estar situado aquí. Nótese al mismo tiempo que la jerarquía de las estupideces coincide perfectamente con la de las vulgaridades en Gombrowicz: el vulgar máximo, que directamente ignora los buenos modales, como el idiota, que ignora cualquier Ley, 
están, por una inversión de valores habitual en Gombrowicz, en el vértice máximo, así como la inmadurez es superior a la madurez, la grosería a las buenas formas. En esta producción temprana de Gombrowicz, efectivamente, se verifica una búsqueda solapada de la distinción en lo bajo que preocupa también a, por ejemplo, Proust (quien precisamente desprecia lo común, pero no lo vulgar). Este proceso está desdibujado en obras posteriores, donde la relación entre clases se vuelve más anárquica. Si uno de los héroes de TransAtlántico, Gonzalo, simula ser mayordomo de su propia mansión para despistar a sus enemigos, esto ya tiene poco que ver con el afán de distinción por la vulgaridad.

En este punto del relato, el matrimonio hace una jugada estúpida y, por eso mismo, adecuada: contrata una criada monstruosa para que Filip no se vea en la tentación de seducirla, cuando, en realidad, son justamente estas empleadas las más tentadoras para Filip. En este contexto empieza un sordo enfrentamiento entre sirviente y patrona. La educación de la criada "asumía aspectos cada vez más crueles, hasta transformarse en una especie de mutilación” (Gombrowicz, 2015, p. 129). Aquí no hay ninguna ficción de asimilación entre clases, sino guerra total que acaba con la muerte o la desaparición. ${ }^{14}$ Nótese la diferencia entre la criada por antonomasia de En busca del tiempo perdido, Françoise, que tiene una incidencia extraordinaria frente a sus patrones, se ocupa de marcar su territorio frente a otras criadas e influye, con su astucia silvestre, en el rumbo (cediendo a veces, imponiéndose otras) de una casa que tiene su política y su diplomacia. A tal punto se integra, que excede su rol, invirtiéndolo: en un punto llega, no solo a oponerse a la relación del narrador con Albertine, sino a denunciar (ella, la empleada doméstica), en los términos más enérgicos, la vulgaridad de la amada.

\section{LA IDENTIFICACIÓN}

Sobre el final, Filip tiene una revelación.

¿Era posible que solo el pecado y la suciedad fuesen profundos? ¿Se ocultaría acaso la profundidad bajo una uña sucia? Escribí con un dedo en un cristal, sin pensar en lo que hacía: “¡Vergüenza a quien abandona la propia suciedad por la pulcritud de los demás! ¡La suciedad siempre es nuestra; la pulcritud, es de los demás!” (Gombrowicz, 2015, p. 130).

El narrador de En busca del tiempo perdido, a diferencia de Gombrowicz, nunca pierde de vista su posición en un entramado social jerárquico y orgánico, por grande que sea la preferencia del señor por el obrero. En una ocasión, el ascensorista del hotel de Balbec le menciona con orgullo el meteórico ascenso social de su hermana. Es una mujer que, pese a ser hermana "de un simple empleado que lo hace a usted subir en ascensor", no se priva de nada. ${ }^{15}$ (Aquí hay un primer guiño, al ser narrado el "ascenso" social de una familia "ascensorista" que hace subir al narrador a su piso). Para empezar, esta hermana "no se va jamás de un cuarto de hotel sin aliviarse en un armario, una cómoda, para dejar un pequeño recuerdo a la mucama que deberá limpiar”; ${ }^{16}$ éste sería un primer signo de distinción, que reproduce, de modo poco halagüeño, el comportamiento real de ciertas clases acomodadas, que ella percibe como adecuado.

A veces, la hermana lleva a cabo la misma hazaña en un coche de alquiler; su recientemente adquirida situación social se lo permite, y su grandeza se manifiesta, precisamente, en que puede permitírselo. El narrador, según su hábito, no hace comentarios valorativos explícitos, pero éstos aquí sobran.

En este punto, lejos de ser paradójico, su proceder (sin el componente de exageración vistosa) es habitual. Los nuevos ricos, como los nuevos nobles, suelen llevar al exceso las conductas que perciben como típicas de su clase de llegada, caricaturizándolos involuntariamente. A título de ejemplo, Norbert Elias describe el modo en que el recién llegado al mundo de la nobleza, al tomar demasiado en serio las reglas, excede la práctica real de los miembros históricos de dicha clase:

Los oficiales nobles se encontraban habitualmente dentro del marco de una proveniencia civilizatoria bastante bien establecida. El sentimiento de hasta qué punto podía llegarse al aplicar modelos aristocráticos en la práctica muy a menudo se 
perdió en la apropiación de dichos modelos por grupos burgueses. Así aprobaron un empleo ilimitado del poder y violencia (Elias, 1992, p. 23).

La observación de Elias puede aplicarse con más razón todavía a otro punto de vista del ascensorista.

La diferencia entre el "yo" (clase aristocrática establecida) y el "ellos" (pequeños obreros y nuevos ricos) se manifiesta de manera irrefutable cuando el ascensorista agradece al narrador su generosa propina: “ $\mathrm{O} h$ ! Gracias, señor. Si todo el mundo tuviera tan buen corazón como usted, no habría más desdichados. Pero como dice mi hermana, siempre hará falta que los haya para que ahora que yo soy rica los pueda joder un poco" ${ }^{\prime 17}$. La distinción consiste en desmarcarse mediante el ágil expediente de perjudicar al subalterno; esa breve frase explica los sentimientos del ascensorista y de su hermana según los puede concebir el narrador, de un modo tan distante que casi puede confundirse con una atribución de resentimiento. Y la diferencia aparece no solamente en las palabras de uno y el silencio del otro, que son indicativas de distintos status, porque uno se jacta de cierto progreso mundano y el otro no tiene necesidad alguna de mencionar el suyo, sino también en el hecho de que, en una situación asimétrica, uno recibe un don y el otro lo entrega, sin contrapartida posible ${ }^{18}$.

\section{Tradición}

La vulgaridad y la particular perspectiva sobre las clases populares permite a estos autores, entre otras cosas, una peculiar situación dentro, contra o al margen de la tradición, según los períodos. Con esto podemos ocuparnos del posicionamiento explícito de Gombrowicz frente a Proust. En ocasiones declara admirarlo. En otras puede decir:

The flaws of Proust's book are enormous and innumerable - a gold mine of defects. His duel with time, based on an exaggerated, naive faith in the power of art - this is the professional mysticism of a crazed aesthete and artist. His psychological analyses could drag out into infinity, for they are only embroidering on observations - they are not exploratory (Gombrowicz, 1988, p. 64).

Estas declaraciones intempestivas anticipan las diferencias en sus respectivas relaciones con la tradición cultural asociada a una lengua, a un país y a una historia.

Proust encarna la superación en la continuidad -que también es ruptura, pero no de un modo vistoso-, con lo más glorioso de la tradición europea: la unión de la novela realista, de frase vivaz y poética al modo de Flaubert, con los grandes frescos de época de las memorias y cartas de grandes franceses como St. Simon, Mme de Sevigné, Chateaubriand, etc., sin excluir el relato sádico, el melodrama, el folletín o la novela sentimental, pero proyectando estos estratos a una grandeza épico-histórica, de carácter proteico, sin precedentes.

Gombrowicz tiene una relación muy distinta con la tradición. Así, en "El diario de Stefan Czarniecki" (Gombrowicz, 2015) un profesor de "historia y literatura nacional" exalta la superioridad de Polonia frente a Europa occidental:

-Señores - decía, mientras se sonaba la nariz con un enorme pañuelo de colores o se rascaba la oreja con el dedo meñique-, ¿qué otra nación ha sido Mesías de las demás naciones? ¿Qué otra, una avanzada de la Cristiandad? ¿Qué nación puede ostentar un príncipe Poniatowski? Veamos, por ejemplo, a los genios y a los precursores de la humanidad, nosotros contamos con tantos como Europa entera -y luego preguntaba de inmediato-: ¿Dante?

-Yo lo sé profesor -gritaba-. ¡Krasinski!

$-¿$ YY Molière?

-¡Fredro!

- ¿Newton?

-iCopérnico!

- ¿Beethoven?

$-i$ Chopin!

$-¿$ Bach? 
-iMoniuszko!

-¡Sacad las conclusiones! -terminaba-. Nuestra lengua es cien veces más rica que la francesa, que, sin embargo, está considerada como una lengua perfecta (Gombrowicz, 2015, p. 227). ${ }^{19}$

Por supuesto, el tono es paródico. El profesor no tiene reparo en mezclar un poeta prerrenacentista como Dante con un poeta romántico como Aleksandr Fredro, a Beethoven con Chopin. Su lista es tan heterogénea como la de la enciclopedia china de Borges, salvo que, para notarlo, uno debe tener presente la tradición cultural polaca; más que la lista de Borges, depende para su comprensión de cierto conocimiento básico de una tradición dada. Sin duda se trata de una burla al nacionalismo, que para elevarse requiere de una comparación perpetua con lo extranjero y es nostálgico y autocompasivo. El narrador, sin duda, habla en broma. Pero un argentino no podría elaborar una lista semejante ni siquiera en broma. Ésa es una de las grandes diferencias entre un argentino o un brasileño y un polaco o un griego, por más que todos pertenezcan a culturas marginales. Por su parte, un francés como Proust no tendría ningún interés en elaborar una comparación como ésta, así como el narrador de En busca del tiempo perdido no tiene necesidad de señalar su pertenencia social, a diferencia de un nouveau riche o de un noble caído en desgracia. Toda su ironía será, por así decir, monolingüe, y en esto, curiosamente, coincidirá con la de una cultura inmadura. Para tener conciencia de su grandeza no le hace falta el espejo de ninguna cultura externa. ${ }^{20}$

\section{VANGUARDIA E INMADUREZ}

La vanguardia no aspira a la novedad, sino a romper con el pasado. ${ }^{21}$ Por eso quizá, para un autor como Gombrowicz, la vanguardia sería imposible en Argentina: no habría ningún pasado con el que romper, algo que de ningún modo es cierto en el caso de la cultura polaca o, para retomar una que menciona Borges en “El escritor argentino y la tradición”, la judía (Borges, 1974, pp. 267-274). Eso, a la vez, podría permitir una literatura verdaderamente nueva y no meramente vanguardista, que viole los viejos modelos por ignorarlos. Esto precisamente es lo que sucedería con Sergio Leone, director de spaghetti western. En este punto, es iluminador el recuerdo de Clint Eastwood, según lo menciona Frayling:

According to Eastwood: "Sergio doesn't really know anything about the West. He is just a good director. I mean, he has his own ideas, and I think the fact that he doesn't know too much about the West is what works for him... I think his open, adolescent-type approach to film - I don't mean this in a derogatory type of way - gave to the film a new look... He did things at the time that American directors would have been afraid of in a Western." Some of these innovations happened, Eastwood believes, because Leone was not acquainted with the Hollywood rulebook. For instance, the Hays Office had long stipulated that a character being struck by a bullet from a gun could not be in the same frame as that gun when it was fired: the effect was too violent. "You had to shoot separately, and then show the person fall. And that was always thought sort of stupid, but on television we always did it that way... And you see, Sergio never knew that, and so he was tying it up... you see the bullet go off, you see the gun fire, you see the guy fall, and it had never been done that way before” (Frayling, 2000, p. 143). ${ }^{22}$

A diferencia de un vanguardista convencional (si se me permite el oxímoron), Leone no rompe con la tradición por rebeldía sino por ignorancia. Es un bárbaro en sentido creativo. Su cercanía con la literatura inmadura es manifiesta. En el cine argentino reciente hay un caso análogo: el inclasificable y brillante José Celestino Campusano, director de El vikingo, Fantasmas de la ruta, Fango, etc. Cuando un reportero de Página 12 le preguntaba si tal parte de esta última película remitía al Western, el director decía que de ninguna manera, que él “aborrece” el Western:

Lo del diálogo entre los líderes parece como cuando en los westerns el jefe blanco se sienta a dialogar con el jefe indio. Acá hay, además, un personaje al que le dicen El Indio, está el tema de la frontera, hay caballos y tiros como en los westerns. ¿La pensó de esa manera? // -Para nada. Aborrezco los westerns.

No conforme con eso, reta al periodista, diciéndole "Lo que pasa es que el cine de Hollywood impuso en el mundo entero la cultura de los Estados Unidos, las imágenes que le son propias, y entonces nosotros 
vemos el mundo a través de los ojos de ellos" (Bernades, 2014). Cuando el periodista insiste, inquiriendo si determinada pelea a cuchillo remitía a la tradición de compadritos o indios, Campusano decía que de ninguna manera, que en su barrio realmente los problemas a veces se resuelven a cuchilladas, y agregaba con irritación: "Yo no trabajo con referencias cinematográficas o culturales." ${ }^{23}$ El reportero intentaba definirlo en relación a una tradición y él se definía por fuera de cualquier tradición, no en contra, ya que su única tradición sería la realidad: "Trato de reflejar las cosas tal como son, y le puedo asegurar que en algunos lugares muchas peleas se siguen resolviendo a cuchillo" (Bernades, 2014, mis itálicas.). ${ }^{24}$ Por supuesto, no escapa a la tradición ni representa la realidad, aunque sí pone en escena un punto de vista social (motoqueros) y localista (Berazategui y aledaños). ${ }^{25}$ Aunque Campusano no lo admita, la forma general de su obra "espontánea" tiene mucho de telenovela y folletín y sus personajes hablan como en una traducción madrileña de una novela de Salgari, intercalando aquí y allá palabras que no concuerdan con la sintaxis elaborada (“¿Hace mucho que no comés? / Lo suficiente como para estar cagado de hambre", Vikingo). Es realmente un cine "del" conurbano, no "sobre" el conurbano, ${ }^{26}$ y por eso mismo puede permitirse sin complejos formas cultas y zurdamente cultas junto a aventuras totales, emocionalidad desbordantes, inconsecuencias.

Los personajes principales están cerca del heroísmo más tradicional, el sentimentalismo es previsible, pero las películas de Campusano son más realistas, en sentido auerbachiano, que cualquier novela o película de los últimos tiempos: se ven las calles de los barrios, los distintos oficios, los modos de producción de los personajes, la circulación de las mercancías. Solo está ausente la situación política más general, algo adecuado ya que muchos barrios son concebidos internamente como autónomos (y esta autonomía soñada tiene mucho de política).

\section{CONCLUSIÓN}

En este sentido, un país joven, como Leone o Campusano, es análogo a la mujer de Filip que, como vimos, declara ignorar (como el artista virgen en un país sin tradición) en qué consiste la suciedad, mientras su marido, que ha sufrido un proceso de civilización, simplemente la desprecia (como un vanguardista europeo a la tradición). Esto también podría explicar la diferencia entre la ruptura que puede llevar a cabo un aristócrata francés o un falso conde polaco. El primero se opone a la tradición desde su interior, forzando sus límites. El segundo se opone a una tradición que con el tiempo se ha vuelto vagamente ajena, inquietante y olvidada.

Frente a la tradición -y ésta ciertamente no es una taxonomía total al modo estructuralista- uno se puede adaptar (escritor de novelas realistas convencionales), sobreadaptar (Proust: violación por exceso), oponer (el rebelde sin máscara: las vanguardias históricas), situar dentro de una descontextualización en un sistema legítimo de ignorancias parciales (el mejor modelo es el "lector salteado" de Macedonio, que practican Barthes o Borges). Así tenemos al neurótico, al paranoide, al criminal, al perverso ${ }^{27}$. Estos modos, por supuesto, también se mezclan. A Gombrowicz, por lo demás, estas maneras pueden parecerle limitadas e inauténticas. Él quizá preferiría la ignorancia adquirida, cultivada y ostentosa de Beckett en la trilogía, o la ignorancia "histórica" de Leone, Campusano o el Gombrowicz que escribe en español, la del esquizofrénico o el idiota (en el sentido de Žižek), que desconoce la ley (las reglas, la tradición) y por eso la viola del modo más neto.

Concluyo con una aparente paradoja: los grandes negadores de la tradición suelen ser extraordinariamente cultos. Hablan contra la tradición pero dentro de ella y desde lo más alto, como Filip, que ama a las criadas monstruosas no a pesar de, sino precisamente por pertenecer al grupo de funcionarios más distinguidos. Campusano, aunque sea un cineasta extraordinario, no es uno de estos grandes negadores. El motivo es sencillo. Cuando niega la tradición, parece fraudulento, no por ignorancia sino por no someter a crítica la tradición implícita en cualquier cultura popular, en Hollywood como en Berazategui. Para Bourdieu, como hemos visto, los desposeídos son los máximos inauténticos porque, como clase-objeto, están condenados a 
ser hablados por los demás o a reproducir el discurso ajeno; cuando los campesinos son típicos, responden a las expectativas de la ciudad.

En este contexto, podría pensarse que los subalternos no pueden hablar ni ser oídos. Gombrowicz se sitúa en la vereda opuesta. Su canillita, en quien "hay más forma, más estilo, más poesía que en todas las revistas que vende" (Grimberg, 2004, p. 108), es la contracara de ese "subalterno" mudo, y Gombrowicz lo contrario del público distinguido sordo. La diferencia está en el receptor: en el que puede oír el estilo del canillita.

La voluntad a la vez esquizofrénica y revolucionaria de tirar todo por tierra, anular los capitales simbólicos y culturales, igualar en la nada, es propia de un anarquista aristocrático.

Como hemos sugerido, la pregunta acerca de si el subalterno puede ser escuchado quizá sea más central que la de si puede hablar. Gombrowicz, que no es él mismo subalterno y que difícilmente podría ser aprovechado para reivindicaciones de clase, puede ser un ejemplo privilegiado para un estudio de este tipo. Retomando la perspectiva de Spivak, los subalternos sí pueden hablar. Pero nadie puede escucharlos. Nosotros agregaríamos: salvo un conde polaco fraudulento, capaz de ver fantasmas y objetos parciales.

\section{REFERENCIAS}

Benjamin, W. (2012). El París de Baudelaire. Buenos Aires, Argentina: Eterna Cadencia.

Bernades, H. (23/05/2014). Creo mucho en el trabajo conjunto (entrevista a José Celestino Campusano). Página 12.

Borges, J. L. (1974). El escritor argentino y la tradición. En Obras completas 1923-1972. Buenos Aires, Argentina: Emecé.

Bourdieu, P. (1976). Les modes de domination. Actes de la recherche en sciences sociales, 2/2-3 (juin), 122-132.

Bourdieu, P. (1972). Les stratégies matrimoniales dans le système de reproduction. Annales. Économies, Sociétés, Civilisations, 27(4-5), 1105-1127.

Bürger, P. (1974). Theorie der Avantgarde. Frankfurt a. M., Deutschland: Suhrkamp.

Deleuze, G. y Guattari, F. (1972-1973). L'anti-Oedipe. Paris, France: Gallimard.

Duchêne, R. (1994). L'impossible Marcel Proust. Paris, France: Laffont.

Elias, N. (1992). Studien über die Deutschen. Frankfurt a.M., Deutschland: Suhrkamp.

Elias, N. (2012). El proceso de la civilización. México D.F., México: Fondo de Cultura Económica.

Frayling, C. (2000). Sergio Leone: Something to Do with Death. London, United Kingdom: Faber \& Faber.

Gasparini, P. (2004). Sobre lo bajo en Gombrowicz y Sarmiento: ciudades, políticas y cuerpos. II Congresso Brasileiro de Hispanistas, São Páulo. Hispanismo 2002. São Paulo, Associação Editorial Humanitas / ABH, 303-307. Recuperado de http://www.proceedings.scielo.br/scielo.php?pid=MSC0000000012002000300045\&script=s ci_arttext

Gombrowicz, W. (1988). Diary. Volume II. Evanston Ill., U.S.A.: Northwestern University Press.

Gombrowicz, W. (2013). Trans-Atlántico. Buenos Aires, Argentina: El cuenco de plata.

Gombrowicz, W. (2014). Ferdydurke. Buenos Aires, Argentina: El cuenco de plata.

Gombrowicz, W. (2015). Bacacy. Buenos Aires, Argentina: El cuenco de plata.

González Tuñón, R. (1933). Parece mentira. Contra, 1.

Grimberg, M. (2004). Evocando a Gombrowicz. Buenos Aires, Argentina: Galerna.

Huerga, C. (2010). Witold Gombrowicz: un polaco en la literatura argentina. Espéculo. Revista de estudios literarios. Recuperado de http://www.ucm.es/info/especulo/numero44/witoldgo.html

Lauwers, J.y Van Parys, T. (2008). "You cannot make a living just being a theoretician”. An interview with Jean-Michel Rabaté. Parrhesia, 5, 1-9.

Mandolessi, S. (2012). Una literatura abyecta. Gombrowicz en la tradición argentina. Amsterdam, Países Bajos: Rodopi. Miller, W. (1997). Anatomy of Disgust. Cambridge, U.S.A.-London, United Kingdom: Harvard University Press. 
Proust, M. (1987). Du côté de chez Swann. Paris, France: La Pléïade.

Proust, M. (1989). Sodome et Gomorrhe. Paris, France: La Pléiade.

Proust, M. (1993). La prisonnière. Paris, France: La Pléïade.

Rússovich, A. (2000). Gombrowicz en el relato argentino. En E. Drucaroff (Ed.), Historia crítica de la literatura argentina. Vol. 11. La narración gana la partida (361-377). Buenos Aires, Argentina: Emecé.

Zagdanski, S. (1994). Le sexe de Proust. Paris, France: Gallimard.

Žižek, S. (2008). For they Know Not. London, United Kingdom: Verso.

Žižek, S. (2012). Less than Nothing. Hegel and the Shadow of Dialectic Materialism. London, United Kingdom: Verso.

\section{Notas}

1 Para el rol de Gombrowicz en la literatura argentina, véase Rússovich, 2000; Huerga, 2010.

2 On Gombrowicz's rol in Argentine literature, see Rússovich, 2000; Huerga, 2010.

3 La célebre traducción pertenece al propio Gombrowicz y a un grupo de colaboradores latinoamericanos. El texto polaco corre así: "Czy wreszcie płatna służąca, istota bez głosu?”. En vez de "mercenaria”, podría optarse por "asalariada”.

4 Para una comparación de lo bajo en Gombrowicz y Sarmiento, véase Gasparini, 2004: "en la oscuridad de Retiro, Gombrowicz se describe persiguiendo a los 'naturales' jóvenes 'del vulgo', esos soldados, lavaplatos, marineros heterogéneos representantes del incipiente país aún por formarse y encarnaciones de esa bajeza entendida y sentida por el escritor polaco como primordial e insustituible belleza".

5 "Il n'y a guère que le sadisme qui donne un fondement dans la vie à l'esthétique du mélodrame" (Proust, 1987, p. 161).

6 Por ejemplo, tras indicarle Aimé al narrador que Albertine tendría "mauvais genre", este responde: "J'avais compris genre vulgaire, parce que pour le contredire d'avance j'avais déclaré qu'elle avait de la distinction" (Proust, 1993, p. 145, mis itálicas). (Sólo después se le ocurre que el “mauvais genre" podía entenderse com "genre gomorrhéen”, es decir de mujeres amantes de mujeres).

7 Cf. Miller (1997, pp. 253-254). Su periodización distingue "heroic society, the ancien regime, and democracy" (207). Suscribo a la idea de Mandolessi (2012) de que Miller y, más en general, los estudios sobre la repugnancia, dan una clave de lectura sólida para la obra de Gombrowicz.

8 “[Hugo] [f]ue el primer gran escritor que usó títulos colectivos en su obra: Les Misérables, Les travailleurs de la mer. La multitud significaba para él, casi en un sentido antiguo, la multitud de los clientes -esto es, sus lectores- y de sus masas de votantes” (Benjamin, 2010, p. 136).

9 Cf. Miller (1997, p. 252): "Sex is what ultimately defeats middle-class solicitude and admiration of lower-class people". Por supuesto, la cuestión de la homosexualidad explica al menos en parte las actitudes de Gombrowicz y Proust. Para el caso del francés, véase la discusión sobre el concepto y la connotación de la inversión en Zagdanski (1994).

10 Para este tema, cf. Bourdieu (1976), Bourdieu (1972).

11 Tras declarar: “je n'avais jamais fait de distinction entre les classes” (Proust, 1989, p. 414): “je n'avais jamais fait de différence entre les ouvriers, les bourgeois et les grands seigneurs, et j'aurais pris indifféremment les uns et les autres pour amis, avec une certaine préférence pour les ouvriers, et après cela pour les grands seigneurs, non par goût, mais sachant qu'on peut exiger d'eux plus de politesse envers les ouvriers qu'on ne l'obtient de la part des bourgeois." Compárese con el proceso que describe Pascal en Pensées: "Le peuple honore les personnes de grande naissance. Les demi-habiles les méprisent, disant que la naissance n'est pas un avantage de la personne, mais du hasard. Les habiles les honorent, non par la pensée du peuple, mais par la pensée de derrière" (Proust, 1989, p. 485). El narrador de En busca del tiempo perdido, al preferir las personas socialmente más brillantes frente a la burguesía porque aquéllos tratan con más miramiento a las clases bajas, tiene un proceder invertido pero simétrico. En ambos casos los extremos se tocan y lo bajo está más cerca de lo alto que lo intermedio.

12 "Pour lui épargner fût-ce au prix d'un chagrin les déceptions qui me semblaient devoir l'attendre, je lui dit que certains hommes, et souvent les plus remarquables par l'intelligence et les plus délicats de sensibilité, ne pouvaient demander la satisfaction de leurs désirs qu'à des femmes extrêmement vulgaires, des filles, des bonnes, quelquefois de femmes des rues" (Proust, 1989, p. 534).

13 Ciertamente, el caso de la mujer de Filip es algo más complejo, ya que es consciente de su ignorancia y, en esta medida, podría tratarse de una snob al cubo (como son snobs al cuadrado quienes practican modales populares por afán de distinción).

14 Deplora, entre otras cosas, que con la presencia de Albertine habita en la casa ella se ve humillada "par le vice, par ce qu'il y a de plus vulgaire et de plus bas" (Proust, 1993, p. 159). 
15 "Et vous ne le croiriez pas, pour la sœur du simple employé qui vous fait monter l'ascenseur" (Proust, 1989, p. 369).

16 "Elle ne quitte jamais un hôtel sans se soulager dans un armoire, une commode, pour laisser un petit souvenir à la femme de chambre qui aura à nettoyer" (Proust, 1989, p. 369).

17 "Oh! Merci, Monsieur. Si tout le monde avait aussi bon cœur que vous, il n'y aurait plus de malheureux. Mais comme dit ma sœur, il faudra toujours qu' il y en ait pour que maintenant que je suis riche, je puisse un peu les emmerder" (Proust, 1989, p. 369).

18 En la época de la Recherche, las propinas tenían una importancia casi inimaginable hoy en día. "Les étrennes et les cadeaux et les dons charitables aux pauvres occupaient alors une place importante dans les budgets bourgeois, de 3 à $7 \%$ des dépenses, plus que les impôts et les assurances, presque autant que les gages” (Duchêne, 1994, p. 71).

19 Referencias "a nuestros Grandes Escritores y a nuestros Genios” aparecen también en Trans-Atlántico (Gombrowicz, 2013, p. 24).

20 El mito de la continuidad de la tradición, si bien bajado a tierra, se mantiene en muchos teóricos de gran vuelo. Véase el caso de J.-M. Rabaté, erudito francés emigrado en Estados Unidos, editor de un popular companion sobre Lacan, quien declara: "I think it is indeed a defining characteristic that, if you are French, it is not simply that you have read certain authors as a student, but also that you are more acquainted with continental philosophy in general than Americans are at the same age. French students will more or less know where to situate philosophers as Heidegger and Hegel, whereas to American students, or even colleagues, these are floating references, for they do not see them within the complex historical context, with names and relationships. Since we have a sense for the cultural background of these philosophers, it is easier for us to gain a broader understanding" (Lauwers-Van Parys, 2008, p. 2). La superioridad se explica en términos del sistema contemporáneo (lecturas reales en el presente) y no históricos (la presencia efectiva de una tradición continua más extensa); con todo, y en la medida en que desembocan en un habitus, el resultado es análogo.

21 La categoría de lo "nuevo" le resultaría inaplicable. Al llevar a cabo un "Traditionsbruch", que conduce a la "Veränderung der künstlerischen Darstellungmittel”, no a una simple renovación (cf. Bürger, 1974, p. 85).

22 Cf. Žižek (2008, lxiv, n. 87), que agrega: "That is the truth of Adorno's aperçu: 'Perhaps, a film strictly obeying the Hays Office code could succeed as a great work of art, but not in a world in which there is a Hays Office".

23 “-Esas peleas a cuchillo parecen de otra época. De indios del siglo XIX o compadritos de hace un siglo. ¿Hay una referencia deliberada a eso? // -Yo no trabajo con referencias cinematográficas o culturales" (Bernades, 2014).

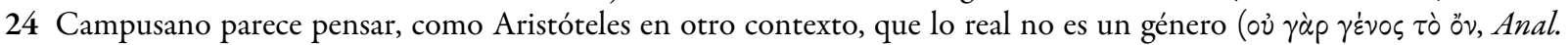
Post. 92b 14): ni Western, ni comedia, ni gauchesco, y creer, a diferencia de Aristóteles, que puede ser representado sin mediación.

25 "Me parece que gran parte del cine argentino es un cine de clase media, que sale poco fuera de su propia realidad, su propia burbuja. Yo muestro lo que tengo alrededor" (Bernades, 2014).

26 Borges emite una idea semejante acerca del poemario Misas herejes de Evaristo Carriego, publicado en 1908: "Las páginas de observación del barrio [...] [r] epiten la valerosa idea que tiene de sí mismo el suburbio, gustaron con entero derecho" (Borges, 1974, p. 142). Duplican la autoconciencia, sin ponerla en cuestión ni problematizarla. El poeta es en todo caso portavoz del barrio, que es su cliente. No ejecuta propiamente una representación; según las categorías que Spivak retoma de Marx, lleva a cabo una Vertretung más que una Darstellung. ¿En qué medida habla en sus versos el subalterno? Cf. Borges (1974, p. 115): "Carriego creía tener una obligación con su barrio pobre: obligación que el estilo bellaco de la fecha traducía en rencor, pero que él sentiría como una fuerza”.

27 Para el neurótico, el paranoico y el perverso, cf. Deleuze-Guattari (1972-1973, p. 43): "Le pervers, c'est celui qui prend l'artifice au mot : vous en voulez, vous en aurez, des territorialités infiniment plus artificielles encore que celles que la société nous propose, de nouvelles familles infiniment artificielles, des sociétés secrètes et lunaires. Quant au schizo, de son pas vacillant qui ne cesse de migrer, d'errer, de trébucher, il s'enfonce toujours plus loin dans la déterritorialisation, sur son propre corps sans organes à l'infini de la décomposition du socius, et peut-être est-ce sa manière à lui de retrouver la terre, la promenade du schizo. Le schizophrène se tient à la limite du capitalisme : il en est la tendance éveloppée, le surproduit, le prolétaire et l'ange exterminateur. Il brouille tous les codes, et porte les flux décodés du désir. Le réel flue."

\section{BY-NC-SA}

